\title{
Health literacy among Iranian adults: findings from a nationwide population-based survey in 2015
}

Ali Akbar Haghdoost, ${ }^{1}$ Mohammad Karamouzian, ${ }^{2,3}$ Ensiyeh Jamshidi, ${ }^{4}$ Hamid Sharifi, ${ }^{2}$ Fatemeh Rakhshani, ${ }^{5}$ Nadia Mashayekhi, ${ }^{6}$ Hamid Rassafiani, Fatemeh Harofteh, ${ }^{8}$ Mansoor Shiri, ${ }^{9}$ Mohammad Aligol, ${ }^{10}$ Hossein Sotudeh, ${ }^{11}$ Atoosa Solimanian, ${ }^{12}$ Fatemeh Tavakoli ${ }^{2}$ and Abedin Iranpour ${ }^{2}$

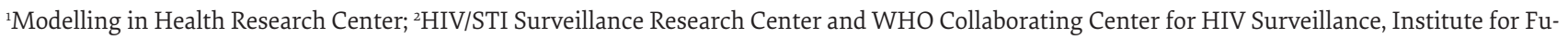
tures Studies in Health, Kerman University of Medical Sciences, Kerman, Islamic Republic of Iran (Correspondence to Abedin Iranpour: a.iranpour@ kmu.ac.ir). ${ }^{3}$ School of Population and Public Health, University of British Columbia, Vancouver, Canada. ${ }^{4}$ Community Based Participatory Research Center, Iranian Institute for Reduction of High -Risk Behaviors, Tehran University of Medical Sciences, Tehran, Islamic Republic of Iran. ${ }^{5}$ School of Public Health, Safety Promotion and Injury Prevention Research Center, Shahid Beheshti University of Medical Sciences, Tehran, Islamic Republic of Iran. ${ }^{6}$ Health Education Office, Department of Health Affairs, Arak University of Medical Sciences, Arak, Islamic Republic of Iran. ${ }^{7}$ Health Education Office, Department of Health Affairs, Bushehr University of Medical Sciences, Bushehr, Islamic Republic of Iran. ${ }^{8}$ Health Education \& Promotion, School of Medical Sciences, Tarbiat Modares University, Tehran, Islamic Republic of Iran. ${ }^{\circ}$ Behavioral Sciences Research Center, School of Medicine, Isfahan University of Medical Sciences, Isfahan, Islamic Republic of Iran. ${ }^{10}$ Department of Health Education and Promotion, School of Health, Shahid Beheshti University of Medical Sciences, Tehran, Islamic Republic of Iran. " Health Education Office, Department of Health Affairs, Zabol University of Medical Sciences, Zabol, Islamic Republic of Iran. ${ }^{12}$ Health Education Office, Health Departments, Ministry of Health and Medical Education, Islamic Republic of Iran.

\begin{abstract}
Background: Health literacy is one of the most important determinants of noncommunicable diseases prevention. Health literacy is associated with elevated risks for poorer access to care, adverse health outcomes, and increased hospitalization and health costs.

Aims: This study aimed to determine the level of health literacy among the general adult population in the Islamic Republic of Iran.

Methods: Using a cross-sectional study during 2014-2015 with a multistage cluster sampling approach, we administered a pilot-tested standardized questionnaire to assess different domains of health literacy (i.e., reading, comprehension, communication/decision-making and Interpretation/judgment skills, individual and social empowerment, health information access and health information use) among 8439 (3935 males) individuals aged 18-60 years. Data were collected through face-to-face interviews. Descriptive statistics and multivariable linear regression method using SPSS (20) were applied to identify the factors associated with health literacy among Iranian adults.

Results: The mean health literacy level was 10.2 \pm 3.8 (out of 20). Only 18\% (95\% confidence interval [CI]: 17.15-18.78) of the participants had adequate health literacy, while 45.7\% (95\% CI: 44.64-46.78) had inadequate, and the 36.3\% (95\% CI: 35.21-37.33) had moderate health literacy. In the adjusted linear regression model, education level (the smallest $\beta=4.35$, $P<0.001)$, age $(\beta=0.01, P=0.002)$, female sex $(\beta=0.45, P<0.001)$, residency in rural areas $(\beta=0.26, P<0.001)$ and having permanent job $(\beta=1.03, P<0.001)$ were significantly associated with more health literacy.

Conclusion: Our findings highlighted that the Iranian adult population has an insufficient level of health literacy, which calls for comprehensive education planning to improve the levels, with special attention to certain subpopulations (e.g. illiterate populations) and domains (e.g. individual empowerment).

Keywords: health literacy, Iranian adult population, questionnaire, empowerment, health information

Citation: Haghdoost A; Karamouzian M; Jamshidi E; Sharifi H; Rakhshani F; Mashayekhi N; et al. Health literacy among Iranian adults: findings from a nationwide population-based survey in 2015. East Mediterr Health J. 2019;25(10):828-836. https://doi.org/10.26719/emhj.19.017

Received: 04/07/18, accepted: 03/01/19

Copyright () World Health Organization (WHO) 2019. Some rights reserved. This work is available under the CC BY-NC-SA 3.0 IGO license https:// creativecommons.org/licenses/by-nc-sa/3.o/igo.
\end{abstract}

\section{Introduction}

Health literacy, defined as "the degree to which individuals have the capacity to obtain, process and understand the basic health information and services needed to make appropriate health decisions", is an increasingly recognized public health concept that mediates the association between health and education $(1,2)$. It is a tool that can empower people to take better control of their health, and eventually leads to the development of social capital (3-5). Health literacy also influences the efficiency and effectiveness of health education and promotion programmes and is one of the most important determinants of noncommunicable disease prevention
(3). Indeed, studies suggest health literacy is a stronger predictor of health compared with other individual characteristics such as income, occupation, educational attainment or age $(3,6)$.

Furthermore, inadequate health literacy is associated with increases in workplace incidents, hospitalization and re-admission rates, morbidity and premature death, and engagement in risky behaviours (e.g. substance use), as well as a decrease in self-care and participation in screening and disease prevention programmes $(1,3)$. Therefore, it is essential to provide health policy-makers with reliable estimates of health literacy to help inform decision-making procedures. While education levels 
have an undeniable role in the health literacy levels of individuals, other factors, such as age, environment, income, ethnicity and communication skills with health care providers, have also been identified as having an influence $(7,8)$.

Insufficient health literacy levels vary greatly across different settings, varying from $54.3 \%$ in Germany to $58 \%$ in Turkey and 28.5\% in England (9-11). Lower levels of health literacy are often observed in developing settings such as the Middle Eastern context (12). In the Islamic Republic of Iran, one of the most populated countries in the Middle East, several studies have tried to measure health literacy and reported overall insufficient health literacy levels, ranging from $41 \%$ in adults in the central province of Yazd to $68 \%$ in the southeastern province of Baluchistan (13). Previous studies have also indicated varying levels of health literacy among different subpopulations of patients, e.g., $70 \%$ insufficient health literacy in patients with diabetes (14); and age groups, e.g., $79.6 \%$ insufficient health literacy among older adults (15). However, the existing body of evidence often suffers from sampling bias (e.g. small sample size, restricted subpopulations, specific geographic areas) and has focused on specific aspects of health literacy, e.g., using the Test of Functional Health Literacy in Adults (TOFHLA), which measures patients' ability to read and understand the concepts of texts in health centres. The only nationwide study with a reasonable sample size was carried out on literate and urban individuals aged 18-65 years; however, it did not cover illiterate and rural areas (16).

Therefore, our study aimed to determine the level of health literacy in the Islamic Republic of Iran, and in particular to address the existing gaps and limitations in the literature. Using the validated Iranian Health Literacy Questionnaire (IHLQ) (17), we aimed to assess all of the important domains of health literacy and factors associated with health literacy in the urban and rural adult population across 9 major provinces.

\section{Methods}

\section{Sampling and data collection}

This cross-sectional household survey was conducted in 9 provinces (out of 31) in the Islamic Republic of Iran between May 2014 and December 2015. Through a multistage sampling scheme, 8950 individuals were recruited, 8439 of whom (3935 men, 4469 women and 35 undefined) were considered eligible for this analysis. Samples were divided equally between rural and urban areas, as well as men and women. All provinces were stratified into 3 levels of low, moderate, and high literacy based on the most recent provincial literacy rates from the Statistical Centre of Iran (18). We divided the provinces in 3 categories based on literacy: category 1 : provinces with low literacy; category 2: provinces with medium literacy; and category 3: provinces with high literacy. In the majority of the provinces, the literacy proportion was high and therefore they were in catego- ry 3. We tried to select provinces based on proportional size, to be representative of the country as a whole, thus 1 province in the low literacy level grouP (Sistan and Baluchestan), 2 provinces from the moderate level (Kerman and Markazi), and 6 provinces from the high literacy level (Mazandaran, Qom, Booshehr, Yazd, Isfahan, and Qazvin) were randomly selected. Primary sampling units each consisting of 30 participants were randomly defined from rural and urban areas in the selected provinces. Based on the population size of selected cities and villages, $1-3$ primary sampling units were enrolled. The sample size for this study was calculated to estimate the level of health literacy with a maximum $5 \%$ deviation with $95 \%$ confidence in each stratum and each subgroup.

Participants were 18-60 years old, Iranian, and able to communicate in Farsi. A systematic random sampling frame was used to inform the selection of households in each municipal area (19). If the house appeared to be occupied but no one was home, interviewers returned at another time. If no resident was available on the return visit, there was no eligible individual in the house, or the eligible respondent refused to participate in the study, an adjacent house was approached. Face-to-face interviews were conducted on the doorstep, taking 15-30 minutes (around 20 minutes for most samples). Participants were briefed about the objectives of the study. The questionnaire was self-administered for literate participants and interviewer-administered (gendermatched) for those who were illiterate.

\section{Questionnaire}

Data were collected using the IHLQ (17). This questionnaire has 53 items in 9 domains: health information access ( 5 items), health information use (6 items), reading skills (5 items), comprehension skills (8 items), interpretation/judgment skills (6 items), communication and decision-making skills (8 items), health knowledge (5 items), individual empowerment (6 items), and social empowerment (4 items). In a previous study, in which we validated our questionnaire, the KaiserMeyer-Olkin coefficient was 0.95, Bartlett's test for sphericity was statistically significant $(P<0.001)$ and Cronbach's alpha was $>0.7(0.71-0.96)(17)$. The intraclass coefficient for each construct varied between 0.60 and 0.81 .

\section{Data analysis}

The analysis explores factors associated with health literacy; this was treated as a categorical variable for descriptive purposes and as a continuous variable for the regression analyses. The main dependent variable in this study was health literacy. So that policy-makers would have a more accurate and clear understanding of it, first the construct scores were calculated using a Likert scale of $0-3$ or $0-4$. Then the final score of each construct was changed to a 0-20 scale.

Overall health literacy score was determined by aggregating correct answers from all questions and 
ranged between 0 and 20. Scores were then categorized into 3 groups: inadequate $(<10)$, moderate $(10-14)$ and adequate ( $>14)$. Independent variables included age, sex, education, residence and occupation. We defined permanent job as a relatively stable job with regular salary in the last year and temporary job as a part-time job in the last year with low assurance for the work to continue.

\section{Statistical analysis}

Univariate and multivariable linear regression models were constructed to investigate the determinants of health literacy. Categorical variables were introduced to the multifactorial model using a series of indicator variables. For example, occupation had 7 categories. We selected one type of job as the reference, and created 6 binary variables, which took values of 0 and 1 . To achieve a higher generalizability of the results, health literacy was standardized using the literacy level [according to the 2011 Population and Housing Census of Iran (18)] of participants as the most important predictor. To estimate the national and subnational health literacy scores, the clustering effect and the sampling weights were computed and applied to all of the descriptive and analytical statistics using random effects models. All analyses were done using SPSS, version 20 , and $P$-values $<5 \%$ were considered statistically significant.

\section{Ethical considerations}

Oral informed consent was obtained from the participants after explaining the goals of the study and assuring their confidentiality. Also, questionnaires were designed to be anonymous. This study obtained ethical approval from the Health Department of the Ministry of Health and Medical Education (Ref. No: 300. 12690).

\section{Results}

\section{Demographic characteristics}

Of the 8950 questionnaires, 8439 (response rate 94.3\%) were considered appropriate for the analysis. The mean age of the participants was 36.7 [standard deviation (SD) 11.5] [36.16 (SD 11.33) for women and 37.33 (SD 11.80) for men]. About $47 \%(n=4469)$ of the participants were male and about $42 \%(n=3557)$ were living in rural areas. Around $35.3 \%(n=2974)$ of the participants had completed elementary or secondary school and $10.8 \%(n=908)$ were illiterate. Most participants were housewives/homemakers (43.7\%), $24.8 \%$ had a permanent job and $4.8 \%$ were retired (Table 1).

The prevalence of literacy among men was significantly higher than women $(92.4 \%$ vs $86.4 \%$; $P<$ 0001). The prevalence of illiteracy in rural and urban areas was $15.5 \%$ and $7.3 \%$, respectively; $13.8 \%$ of rural and $27.3 \%$ of urban participants had a university degree.

\section{Health literacy status}

Figure 1 shows health literacy levels among men and women. The mean health literacy level was 10.2 (SD 3.8) (on a scale of 0-20). Overall, $45.7 \%$ of the participants had inadequate $(<10)$ and $18 \%$ had adequate $(>14)$ health literacy scores.

More than $95 \%$ of the illiterate participants had an inadequate health literacy level, and only $41 \%$ of those with a university degree had an adequate health literacy

\begin{tabular}{|c|c|c|c|c|}
\hline Characteristic & $\begin{array}{c}\text { Females } \\
(n=4469)\end{array}$ & $\begin{array}{c}\text { Males } \\
(n=3935)\end{array}$ & $\begin{array}{c}\text { Total } \\
(n=8404)\end{array}$ & $P$-value \\
\hline \multirow[t]{2}{*}{ Mean (SD) age (years) } & $36.16(11.33)$ & $37.33(11.80)$ & $36.7(11.5)$ & \multirow[t]{2}{*}{$<0.001$} \\
\hline & No. $(\%)$ & No. $(\%)$ & No. (\%) & \\
\hline \multicolumn{5}{|l|}{ Residence $(\mathrm{n}=8038)$} \\
\hline Urban & $2578(57.7)$ & $2288(58.2)$ & $4482(58.0)$ & \multirow[t]{2}{*}{0.61} \\
\hline Rural & $1819(42.3)$ & $1646(41.8)$ & $3556(42.0)$ & \\
\hline \multicolumn{5}{|l|}{ Occupation $(n=8363)$} \\
\hline Student & $288(6.5)$ & $371(9.5)$ & $659(7.9)$ & \multirow[t]{6}{*}{$<0.001$} \\
\hline Housewife/homemaker & $3458(77.7)$ & $193(4.9)$ & $3651(43.7)$ & \\
\hline Retired & $56(1.3)$ & $342(8.7)$ & $398(4.8)$ & \\
\hline Unemployed & $89(2.0)$ & $351(9.0)$ & $440(5.3)$ & \\
\hline Permanent job & $345(7.7)$ & $1731(44.3)$ & $2076(24.8)$ & \\
\hline Temporary job & $216(4.9)$ & $923(23.6)$ & $1139(13.6)$ & \\
\hline \multicolumn{5}{|l|}{ Education level } \\
\hline Illiterate & $607(13.6)$ & $298(7.6)$ & $905(10.8)$ & \multirow{4}{*}{$<0.001$} \\
\hline Elementary and secondary & $1631(36.5)$ & $1339(34.1)$ & $2970(35.3)$ & \\
\hline High school & $1392(31.2)$ & $1317(33.5)$ & $2709(32.3)$ & \\
\hline College/university & $834(18.7)$ & 977 (24.9) & $1811(21.6)$ & \\
\hline
\end{tabular}

SD = standard deviation. 




level (Figure 2). Regarding health literacy domains, the highest score for inadequate health literacy was for "individual empowerment" 6775 (73.2\%), and for adequate health literacy was for "communication and decisionmaking skills" 3903 (46.3\%) (Table 2).

\section{Association of health literacy and independent variables}

The crude health literacy score decreased with age, while it significantly increased with age in the adjusted models $(P=0.01)$. In the crude model, the mean HL score for



Table 2 Distribution of health literacy domain scores among Iranian adults $(n=8434)$

\begin{tabular}{lccc} 
Domain & $\begin{array}{c}\text { Adequate } \\
\text { (No.) }\end{array}$ & $\begin{array}{c}\text { Moderate } \\
\text { (No.) }\end{array}$ & $\begin{array}{c}\text { Inadequate } \\
\text { (No.) }\end{array}$ \\
\hline $\begin{array}{l}\text { Individual } \\
\text { empowerment }\end{array}$ & 733 & 1379 & 5775 \\
$\begin{array}{l}\text { Health information } \\
\text { access }\end{array}$ & 2473 & 1473 & 4488 \\
$\begin{array}{l}\text { Health information use } \\
\text { (previous month) }\end{array}$ & 1275 & 3088 & 4067 \\
$\begin{array}{l}\text { Health knowledge } \\
\begin{array}{l}\text { Interpretation/ } \\
\text { judgment skills }\end{array}\end{array}$ & 3054 & 2082 & 3924 \\
$\begin{array}{l}\text { Comprehension skills } \\
\text { Reading skills }\end{array}$ & 2295 & 2261 & 3868 \\
$\begin{array}{l}\text { Social empowerment } \\
\text { Communication/ } \\
\text { decision-making skills }\end{array}$ & 2774 & 2635 & 3632 \\
\hline
\end{tabular}

women was lower than that of men, but this was reversed in the adjusted regression model $(P=0.01)$. There was a significant association between literacy level and health literacy level in both the crude and adjusted models, and this association increased with increasing literacy level. In the adjusted regression model, people who had a permanent job had a significantly higher health literacy level than other occupation categories. In the crude model, the health literacy score of city dwellers was higher than that of rural residents by 0.80 . However, in the adjusted model, the health literacy score of rural residents was higher than that of city dwellers by 0.26 , and this was statistically significant $(P<001)$ (Table 3$)$.

\section{Discussion}

This was a comprehensive study of health literacy in the Islamic Republic of Iran using a culturally-specific, reliable and valid questionnaire capable of revealing a realistic representation of health literacy.

According to a recent systematic review and meta-analysis, the most common instrument used in measuring health literacy in the Islamic Republic of Iran was TOFHLA (20). As noted by Haun et al., a proper health literacy instrument should measures multiple aspects of literacy, including interaction, numeracy comprehension, reading comprehension, information search, decision-making, evaluation, responsibility, self-efficacy, and diagnosis (21): TOFHLA only addresses reading and numeracy comprehension and evaluation. Our study was performed using the IHLQ: the constructs of this questionnaire are based on the health promotion approach and, to a certain extent, it displays the features of a good health literacy instrument.

We found that about $46 \%$ of the participants had low health literacy levels which was associated with certain sociodemographic characteristics including age, sex, education, occupation status and residence (rural/urban). 


\begin{tabular}{|c|c|c|c|c|c|}
\hline \multirow[t]{2}{*}{ Characteristic } & \multirow[t]{2}{*}{$\begin{array}{c}\text { Health } \\
\text { literacy score }\end{array}$} & \multicolumn{2}{|c|}{$\begin{array}{l}\text { Simple linear regression } \\
\text { (crude) }\end{array}$} & \multicolumn{2}{|c|}{ Adjusted } \\
\hline & & $\boldsymbol{\beta}$ & P-value & $\beta$ & P-value \\
\hline Age & & -0.06 & $<001$ & 0.01 & 0.002 \\
\hline \multicolumn{6}{|l|}{ Sex } \\
\hline Female & 10.1 & - & $<0.001$ & - & - \\
\hline Male & 10.4 & 0.27 & & -0.45 & $<0.001$ \\
\hline \multicolumn{6}{|l|}{ Education } \\
\hline Illiterate & 4.9 & - & - & - & - \\
\hline Elementary and secondary education & 9.2 & 4.23 & $<0.001$ & 4.35 & $<0.001$ \\
\hline High school & 11.3 & 6.35 & $<0.001$ & 6.63 & $<0.001$ \\
\hline College/university education College/University & 13.1 & 8.15 & $<0.001$ & 8.48 & $<0.001$ \\
\hline \multicolumn{6}{|l|}{ Occupation } \\
\hline Student (school/university) & 11.7 & - & - & - & - \\
\hline Permanent job & 11.4 & -0.37 & 0.03 & 1.03 & $<0.001$ \\
\hline Retired & 10.3 & -1.41 & $<0.001$ & 0.57 & 0.009 \\
\hline Housewife/homemaker & 9.6 & -2.13 & $<0.001$ & 0.40 & 0.008 \\
\hline Unemployed & 9.1 & -2.62 & $<0.001$ & -0.50 & 0.01 \\
\hline Temporary job & 9.8 & -1.94 & $<0.001$ & 0.09 & 0.56 \\
\hline \multicolumn{6}{|l|}{ Residence } \\
\hline Rural & 9.8 & - & - & - & - \\
\hline Urban & 10.6 & 0.80 & 0.001 & -0.26 & $<0.001$ \\
\hline
\end{tabular}

Our findings were consistent with an existing body of international and national evidence. The findings of several national studies suggest a relatively low level of health literacy in the Islamic Republic of Iran (14,15,2023). For instance, in a study among the literate urban population $>44 \%$ of participants had inadequate and only $16 \%$ had adequate health literacy levels (16).

Our finding that only $18 \%$ of the participants of this nationwide study had sufficient health literacy is very concerning given the impact of limited health literacy on people's ability to promote, protect and manage a healthy lifestyle. This has critical implications for Iranian health care professionals and policy-makers, such as in the ministries of education, culture, and health and medical education as well as in nongovernmental organizations, affecting endeavours to design a comprehensive health promotion programme to systematically improve health literacyacross all societal and economic levels.

As expected, and as observed in previous studies $(10,16,23-27)$, health literacy was significantly associated with higher levels of education. This has significant implications for health sectors given that individuals with no or little educational attainment have been shown to be 5 times more likely to engage in unhealthy behaviours, which could raise their chance of developing poorer health outcomes and widen the health gap between the least and most educated (28).

Although the most important variable influencing health literacy in our study was level of education, and those with higher education had better health literacy, less than half of the respondents with a college/ university degree and only around one-fifth of those with a high school education had adequate health literacy. This indicates that, in addition to general education, the attendance at specific courses in the fields of health skills and health promotion in formal education are crucial to improve health literacy and health skills among communities.

We also observed that people with permanent jobs had higher levels of health literacy, which is consistent with the findings of similar studies in Australia (29), Japan (30) and Italy (31). Perhaps people with permanent jobs had better access to health information in their work environment and had more financial resources to access the health care system and health workers. It could also be attributed to the higher educational attainments required to secure a permanent job $(15,32)$, which may affect socioeconomic status, both of which are associated with higher health literacy levels (9).

We found that some male respondents selected "housewife" as their job. This was because their wives were employed and they took the responsibility of managing the house and children. We understood that this happen in families where the wife has a good salary.

In the present study, the adjusted health literacy among Iranian women was slightly higher than among men, which is in line with the results of similar studies elsewhere $(23,32-35)$. Such a difference could be due to the 


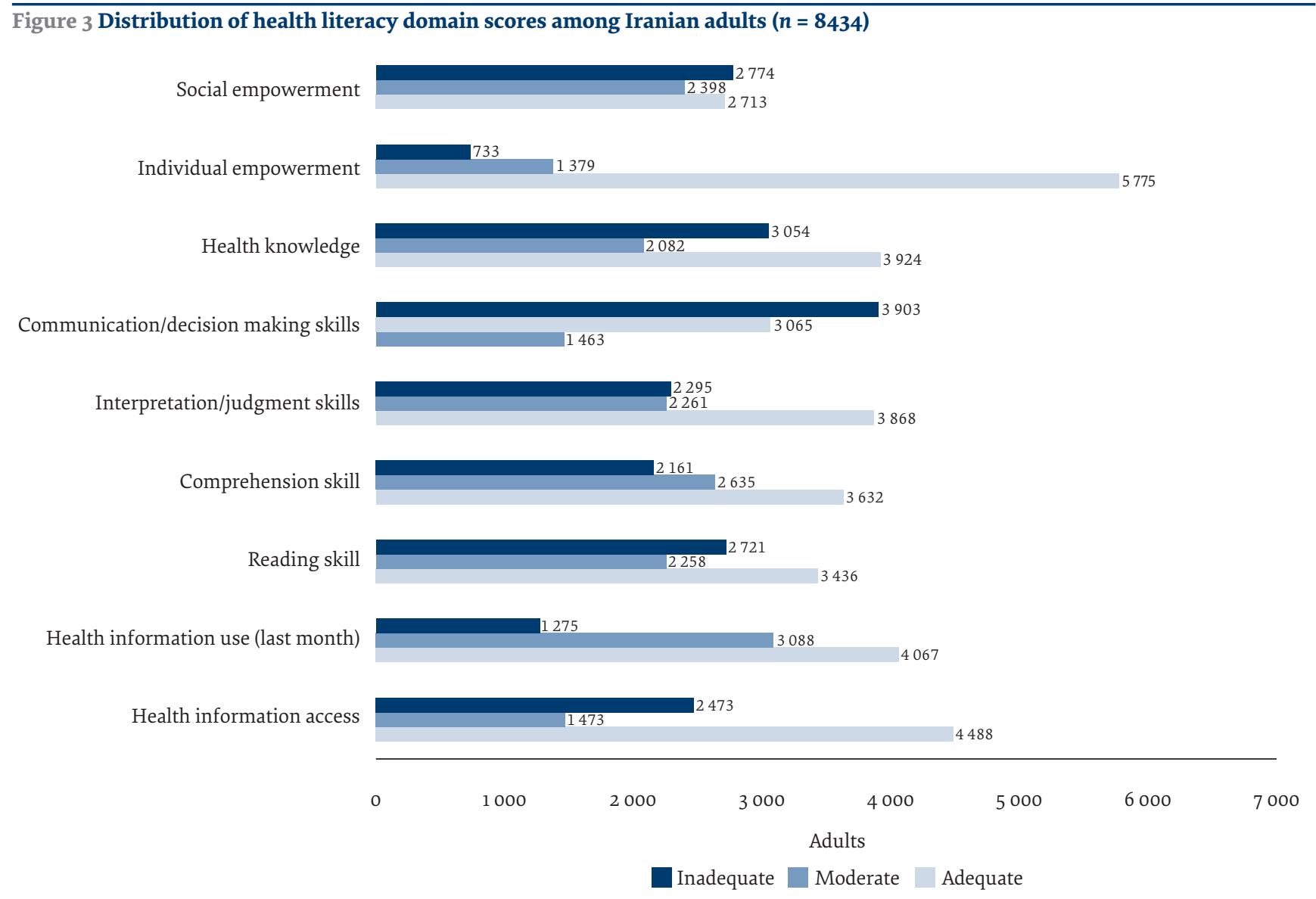

greater use of health information resources by women, higher rates of reporting health issues and seeking care, and their familiarity in navigating the health care system. Moreover, most women included in our study were housewives/homemakers $(77.7 \%)$, who are more likely to be exposed to educational materials broadcast on multimedia.

Additionally, health literacy levels showed a slight increase with older age. This is inconsistent with the results of other studies, which were conducted using TOFHLA $(16,23,6,27,29,36,37)$. This maybe due to differences in the type of questionnaires used: TOFHLA measures the abilities of individuals in clinical behaviours. This may also be due to the higher familiarity among youth with new science and technology. Our findings are also consistent with the findings of Barber et al., who used the Rapid Estimate of Adult Literacy in Medicine (REALM) questionnaire (29). This may be a result of the increased experience of individuals in dealing with health-related determinants and the improvement in their communication, judgment and decision-making skills, which come with older age. It should be noted that the IHLQ has relative similarity in content with the REALM questionnaire.

In this study, health literacy level was higher in rural populations than in city dwellers, which is inconsistent with the findings of Banihashemi et al. $(23,38)$. This is probably due to the differences between the questionnaires used in the 2 studies. In the IHLQ, the ability to access and use health resources is specifically assessed in domains of health literacy. The use of healthrelated resources is more prevalent in rural than in urban areas. Rural populations have greater and easier access to physicians and health care workers - 2 important sources of health information. This difference may be due to the family physician programme, although there is a need for further studies. At the time we conducted the study, the family physician programme had been operating for 10 years (in the rural areas of the country only).

This survey had several limitations. Although the sample was large and nationwide, the home-based nature of the sample, where some potential participants were not at home, may to some extent have limited the study's generalizability and introduced bias. Moreover, social desirability bias could not be ruled out owing to the self-reported nature of the data. The anonymity of the questionnaires and the use of experienced interviewers, however, may have encouraged the participants to provide honest responses. On the other hand, the high response rate in our study ( 94\%) suggests the suitability of the questionnaire and the proper implementation of the research process. Moreover, the large sample size and diversity of sampling points in this study increases the reliability of the results. Overall, given the scope of the study, we believe our findings have important implications for both health research and policy in the Islamic Republic of Iran. 


\section{Conclusion}

Our findings showed that about $46 \%$ of adults have a low HL level. This can affect the ability of people in promoting, maintaining and managing their health. Therefore, at policy-making and decision-making levels, strategic planning for improving HL should focus on increasing literacy in the population, providing permanent job opportunities, improving individual empowerment, health information access, health information use and interpre- tation/judgment skills, and targeting urban areas. Given the different results yielded using different HL tools, future HL studies in the Islamic Republic of Iran could benefit from, and should utilize, culturally-sensitive and context-specific HL tools.

Funding: This research was funded by Kerman University of Medical Sciences.

Competing interests: None declared.

\section{Les connaissances en santé chez les adultes iraniens : résultats d'une enquête en population nationale menée en 2015 \\ Résumé}

Contexte : Les connaissances en santé comptent parmi les déterminants les plus importants de la prévention des maladies non transmissibles. Elles sont associées à des risques élevés de détérioration de l'accès aux soins, de résultats défavorables pour la santé et d'augmentation des coûts d'hospitalisation et de santé.

Objectifs : La présente étude visait à déterminer le niveau de connaissances en santé parmi la population adulte générale en République islamique d'Iran.

Méthodes: Dans le cadre d'une étude transversale menée en 2014-2015 selon une approche d'échantillonnage en grappes à plusieurs degrés, nous avons administré un questionnaire normalisé mis à l'essai afin d'évaluer les différents domaines de connaissances en santé (lecture, compréhension, communication/prise de décision et compétences en interprétation/jugement, autonomisation sociale, accessibilité et utilisation de l'information sanitaire et utilisation de cette dernière) chez 8439 personnes (3935 hommes) âgées de 18 à 60 ans. Les données ont été recueillies lors d'entretiens en présentiel. Des statistiques descriptives et une méthode de régression linéaire multivariables ont été appliquées au moyen du SPSS (2.0) pour identifier les facteurs associés aux connaissances en santé chez les adultes iraniens.

Résultats : Le niveau moyen de connaissances en santé était de 10,2 \pm 3,8 (sur 20). Seuls $18 \%$ des participants (intervalle de confiance à $95 \%$ [IC] : 17,15-18,78) présentaient un niveau de connaissances en santé suffisant, alors que 45,7\% (IC à $95 \%$ : 44,64-46,78) avaient un niveau insuffisant, et 36,3\% (IC à $95 \%$ : 35,21-37,33 ) affichaient un niveau modéré de connaissances en santé. Dans le modèle de régression linéaire ajusté, le niveau d'éducation (plus petit $\beta=4,35$, valeur $p<0,001)$, l'âge $(\beta=0,01$, valeur $p=0,002)$, le sexe féminin $(\beta=0,45$, valeur $p<0,001)$, la résidence en zones rurales $(\beta=0,26$, valeur $p<0,001)$ et le fait d'avoir un emploi permanent $(\beta=1,03$, valeur $p<0,001)$ étaient associés de manière significative à un niveau plus élevé de connaissances en santé.

Conclusion: Les résultats mettent en évidence le niveau insuffisant de connaissances en santé dans la population iranienne adulte, ce qui appelle à la mise en place de plans éducatifs en amont et en aval afin d'améliorer le niveau de connaissances en santé. Ces plans devraient accorder une attention particulière à certaines sous-populations (par exemple les populations analphabètes) et certains sous-domaines (par exemple l'autonomisation des individus).

$$
\begin{aligned}
& \text { عحو الأمية الصحية بين البالغين الإيرانيين: نتائج لمسح سكاني وطني في عام } 10 \text {. }
\end{aligned}
$$

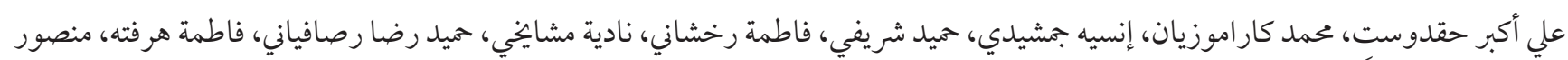

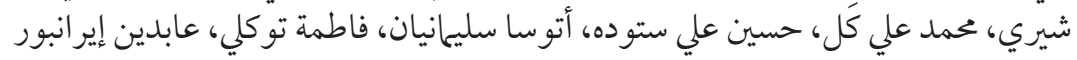

$$
\begin{aligned}
& \text { الأهداف: هدفت هذه الدراسة إلى تحديد مستوى الإلمام الصحي بين عامة البالغين في إيران. }
\end{aligned}
$$

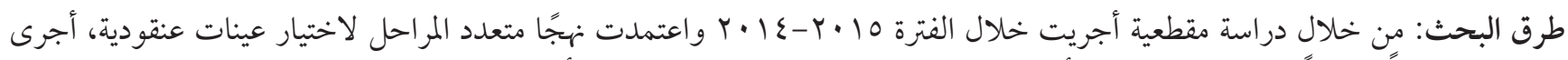



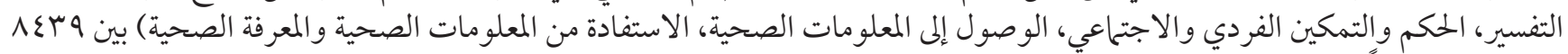



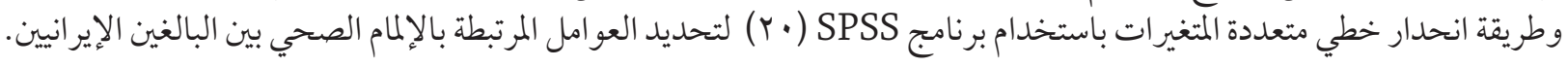




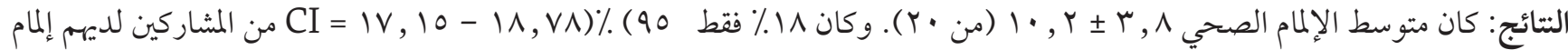

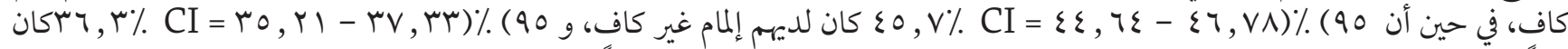

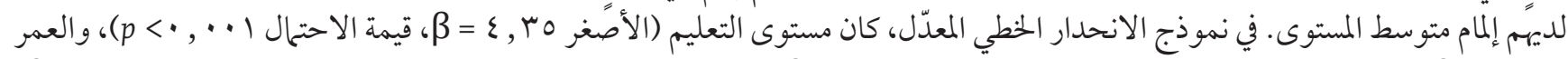

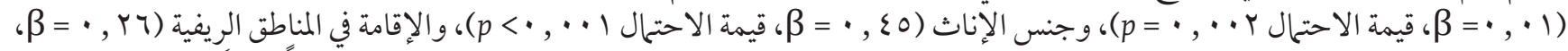

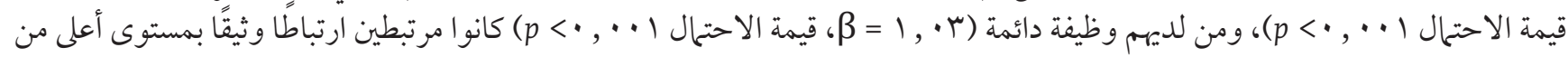
الإلمام الصحي.

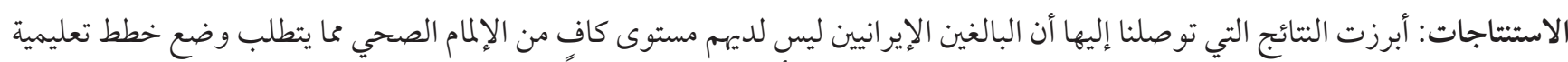

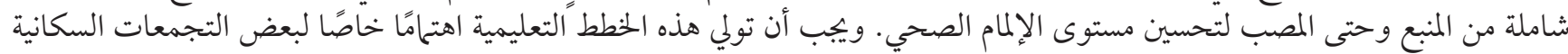

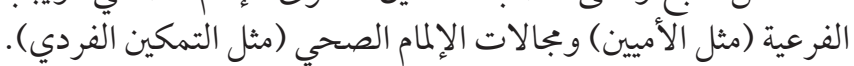

\section{References}

1. Berkman ND, Sheridan SL, Donahue KE, Halpern DJ, Crotty K. Low health literacy and health outcomes: an updated systematic review. Ann Intern Med. 2011 Jul 19;155(2):97-107. doi:10.7326/0003-4819-155-2-201107190-00005

2. Ratzan CS, Parker R, Selden RC, Zorn M. Current bibliographies in medicine 2000-1: Health Literacy. Bethesda: National Institutes of Health; 2000.

3. Kickbush I, Pelikan J, Apfel F, Tsouros A. Health literacy: the solid facts. Copenhagen: World Health Organization Regional Office for Europe: 2013.

4. Roundtable on Health Literacy: Board on Population Health and Public Health Practice. Health literacy: improving health, health systems, and health policy around the world: workshoP summary. Washington DC: National Academies Press; 2013.

5. Sørensen K, Pelikan JM, Röthlin F, Ganahl K, Slonska Z, Doyle G, et al. Health literacy in Europe: comparative results of the European health literacy survey (HLS-EU). Eur J Public Health. 2015 Dec;25(6):1053-8. doi 10.1093/eurpub/ckvo43

6. Moss TR. The impact of health literacy on clinical outcomes for adults with type 2 diabetes mellitus. Advance Diabet Metabol. 2014;2(1):10-9. doi:10.13189/adm.2014.020103

7. Kindig DA, Panzer AM, Nielsen-Bohlman L. Health literacy: a prescription to end confusion: Washington DC: National Academies Press; 2004.

8. Paasche-Orlow MK, Parker RM, Gazmararian JA, Nielsen-Bohlman LT, Rudd RR. The prevalence of limited health literacy. J Gen Intern Med. 2005;20(2):175-84. doi:10.1111/j.1525-1497.2005.40245.X

9. Schaeffer D, Berens E-M, Vogt D. Health literacy in the German population: results of a representative survey. Dtsch Arztebl Int. 2017 Jan 27;114(4):53-60. doi:10.3238/arztebl.2017.0053

10. Bodur AS, Filiz E, Kalkan I. Factors affecting health literacy in adults: a community based study in Konya, Turkey. Int J Caring Sci. 2017;10(1):100.

11. Protheroe J, Whittle R, Bartlam B, Estacio EV, Clark L, Kurth J. Health literacy, associated lifestyle and demographic factors in adult population of an English city: a cross-sectional survey. Health Expect. 2017 Feb;20(1):112-9. doi:10.1111/hex.12440

12. Nair SC, Satish KP, Sreedharan J, Ibrahim H. Assessing health literacy in the eastern and middle-eastern cultures. BMC Public Health. 2016 Aug 19;16:831. doi:10.1186/s12889-016-3488-9

13. Izadirad H, Zareban I. The relationshiP of health literacy with health status, preventive behaviors and health services utilization in Baluchistan, Iran. J Educ Community Health. 2015;2(3):43-50.

14. Mohammadi Z, Banihashemi AT, Asgharifard H, Bahramian M, Baradaran HR, Khamseh ME. Health literacy and its influencing factors in Iranian diabetic patients. Med J Islam Repub Iran. 2015 Jul 11;29:230.

15. Reisi M, Javadzade SH, Mostafavi F, Sharifirad G, Radjati F, Hasanzade A. RelationshiP between health literacy, health status, and healthy behaviors among older adults in Isfahan, Iran. J Educ Health Promot. 2012;1:31. doi:10.4103/2277-9531.100160

16. Tavousi M, Haeri Mehrizi A, Rafiefar S, Solimanian A, Sarbandani F, Ardestani M, et al. Health literacy in Iran: findings from a National study. Payesh. 2016;15(1):103-111.

17. Haghdoost AA, Rakhshani F, Aarabi M, Montazeri A, Tavousi M, Solimanian A, et al. Iranian health literacy questionnaire (IHLQ): an instrument for measuring health literacy in Iran. Iran Red Crescent Med J. 2015 Jun 1;17(6):e25831. doi:10.5812/ircmj.17(5)2015.25831

18. Selected findings of the 2011 national population and housing census. Tehran: Statistical Center of Iran; 2016 (https://www.amar. org.ir/english/Population-and-Housing-Censuses, accessed 27 July 2019).

19. Designing household survey samples: practical guidelines. New York: United Nations Statistics Division; 2005 (Studies in Methods Series F No.98).

20. Dadipoor S, Ramezankhani A, Aghamolaei T, Rakhshani F, Safari-Moradabadi A. Evaluation of health literacy in the Iranian population. Health Scope. 2018;7(3):e62212.

21. Haun JN, Valerio MA, McCormack LA, Sørensen K, Paasche-Orlow MK. Health literacy measurement: an inventory and descrip- 
tive summary of 51 instruments. J Health Commun. 2014;19 Suppl 2:302-33. doi:10.1080/10810730.2014.936571

22. Salimi M, Sarchahi S, Zolfaghari P, Daghyanous B, Mozaffari H, Montazeri M, et al. Health literacy among patients with diabetes mellitus type 2 in northeast area of Iran. Int J Health Studies. 2017;3(1):14-18.

23. Banihashemi S-AT, Amirkhani MA, Tehrani A, Alavian S-M, Asgharifard H, Parsinia S, et al. Health literacy and the influencing factors: a study in five provinces of Iran. Strides Dev Med Educ. 2007;4:1-9.

24. Levinthal BR, Morrow DG, Tu W, Wu J, Murray MD. Cognition and health literacy in patients with hypertension. J Gen Intern Med. 2008 Aug;23(8):1172-6. doi:10.1007/s11606-008-0612-2

25. BeauchamP A, Buchbinder R, Dodson S, Batterham RW, Elsworth GR, McPhee C, et al. Distribution of health literacy strengths and weaknesses across socio-demographic groups: a cross-sectional survey using the Health Literacy Questionnaire (HLQ). BMC Public Health. 2015 Jul 21;15:678. doi:10.1186/s12889-015-2056-Z

26. Ao X, Liu M, Gan Y, Wang H. [Health literacy survey among permanent resident in Daxing District of Beijing]. Wei Sheng Yan Jiu [J Hygiene Res]. 2014;43(1):73-7 [in Chinese]. PMID:24564115

27. Von Wagner C, Knight K, Steptoe A, Wardle J. Functional health literacy and health-promoting behaviour in a national sample of British adults. J Epidemiol Community Health. 2007 Dec;61(12):1086-90. doi:10.1136/jech.2006.053967

28. Buck D, Frosini F. Clustering of unhealthy behaviours over time. London: The Kings Fund. 2012:1-24.

29. Barber MN, Staples M, Osborne RH, Clerehan R, Elder C, Buchbinder R. UP to a quarter of the Australian population may have suboptimal health literacy depending upon the measurement tool: results from a population-based survey. Health Promot Int. 2009 Sep;24(3):252-61. doi:10.1093/heapro/dapo22

30. Suka M, Odajima T, Okamoto M, Sumitani M, Igarashi A, Ishikawa H, et al. RelationshiP between health literacy, health information access, health behavior, and health status in Japanese people. Patient Educ Couns. 2015 May;98(5):660-8. doi:10.1016/j. pec.2015.02.013

31. Palumbo R, Annarumma C, Adinolfi P, Musella M, Piscopo G. The Italian Health Literacy Project: Insights from the assessment of health literacy skills in Italy. Health Policy. 2016 Sep;120(9):1087-94. doi:10.1016/j.healthpol.2016.08.007

32. Rikard RV, Thompson MS, McKinney J, BeauchamP A. Examining health literacy disparities in the United States: a third look at the National Assessment of Adult Literacy (NAAL). BMC Public Health. 2016 SeP 13;16:975. doi:10.1186/s12889-016-3621-9

33. Kutner M, Greenburg E, Jin Y, Paulsen C. The health literacy of America's adults: results from the 2003 national assessment of adult literacy. Washington DC: National Center for Education Statistics; 2006 (NCES 2006-483).

34. Nakayama K, Osaka W, Togari T, Ishikawa H, Yonekura Y, Sekido A, et al. Comprehensive health literacy in Japan is lower than in Europe: a validated Japanese-language assessment of health literacy. BMC Public Health. 2015 May 23;15:505. doi:10.1186/ s12889-015-1835-X

35. von Wagner C, Knight K, Steptoe A, Wardle J. Functional health literacy and health-promoting behaviour in a national sample of British adults. J Epidemiol Community Health. 2007;61(12):1086-90. doi:10.1136/jech.2006.053967

36. Sahm LJ, Wolf MS, Curtis LM, McCarthy S. Prevalence of limited health literacy among Irish adults. J Health Commun. 2012;17 Suppl 3:100-8. doi:10.1080/10810730.2012.718041

37. Buchbinder R, Hall S, Youd JM. Functional health literacy of patients with rheumatoid arthritis attending a community-based rheumatology practice. J Rheumatol. 2006;33(5):879-86. PMID:16511936

38. Zahnd WE, Scaife SL, Francis ML. Health literacy skills in rural and urban populations. Am J Health Behav. 2009 Sep-

Oct;33(5):550-7. PMID:19296745 